\title{
PMIP Past to Future Working Group
}

Julia C. Hargreaves

\begin{abstract}
The Past to Future Working Group enables paleoclimate information from both PMIP models and climate proxies to be used to better constrain predictions of future climate change.
\end{abstract}

\section{Strategy}

The Past to Future Working Group (P2F;

pmip.Isce.ipsl.fr/working_groups/Past2Future) was formed to enable paleoclimate information from both PMIP models and climate proxies to be used to better constrain predictions of future climate change. The remit of the group is wide; in principle any spatial and temporal scales of change and any metric of the climate system may be considered. Here we mostly focus on the equilibrium response of the climate system. In this context the most significant progress over the last few years has been made in better defining and constraining climate sensitivity. Related work focusing on variability is reported elsewhere in this issue. Paleoclimate model simulations were included in the fifth iteration of the Climate Model Intercomparison Project (CMIP5), making this the first time that ensembles of historical, paleo, and future projections were run with the same model versions. In anticipation of this, the P2F group was initiated at the 2012 PMIP3 workshop in Crewe, UK (Crucifix et al. 2012). The overarching purpose of the group was to encourage the use of paleoclimatic information to improve predictions of climate change.

As a cross-cutting group, the main focus of P2F was to facilitate research activities. The working group website was used to improve accessibility to outputs from model simulations and data from climate proxies, and to highlight relevant publications in the field. The main meeting point has been at the European Geophysical Union General Assembly, where there have been a variety of EGU sessions with a focus on Past to Future activities. There have also been several workshops with a significant Past to Future element. Connections between the Cloud Feedback Model Intercomparison Project (CFMIP; cfmip.org) and PMIP have strengthened through the activities of the working group. Joint experiments have been planned; scientists from CFMIP have given keynote presentations at PMIP (and viceversa); and there are a number of scientists who are active in both MIPs.

The status of early research focused on com bining models and data from paleoclimates to constrain predictions of future climate change is well described by Schmidt et al. (2014). This paper outlines various methodologies, illustrated by examples, each of which "uses a specific target (or targets) from a palaeo-climate reconstruction of change that is within the scope of the modelled system, defines a metric of skill that quantifies the accuracy of the modelled changes and assesses the connection to a future prediction". The P2F group promoted a very similar methodology for using the CMIP ensemble, and additionally, highlighted a number of research targets, including:

- Estimating future climate by exploring information from multiple PMIP intervals;

- Exploring divergent estimates of climate sensitivity-towards reconciliation; and

\section{(A) Last Glacial Maximum SAT reconstruction and proxy data}

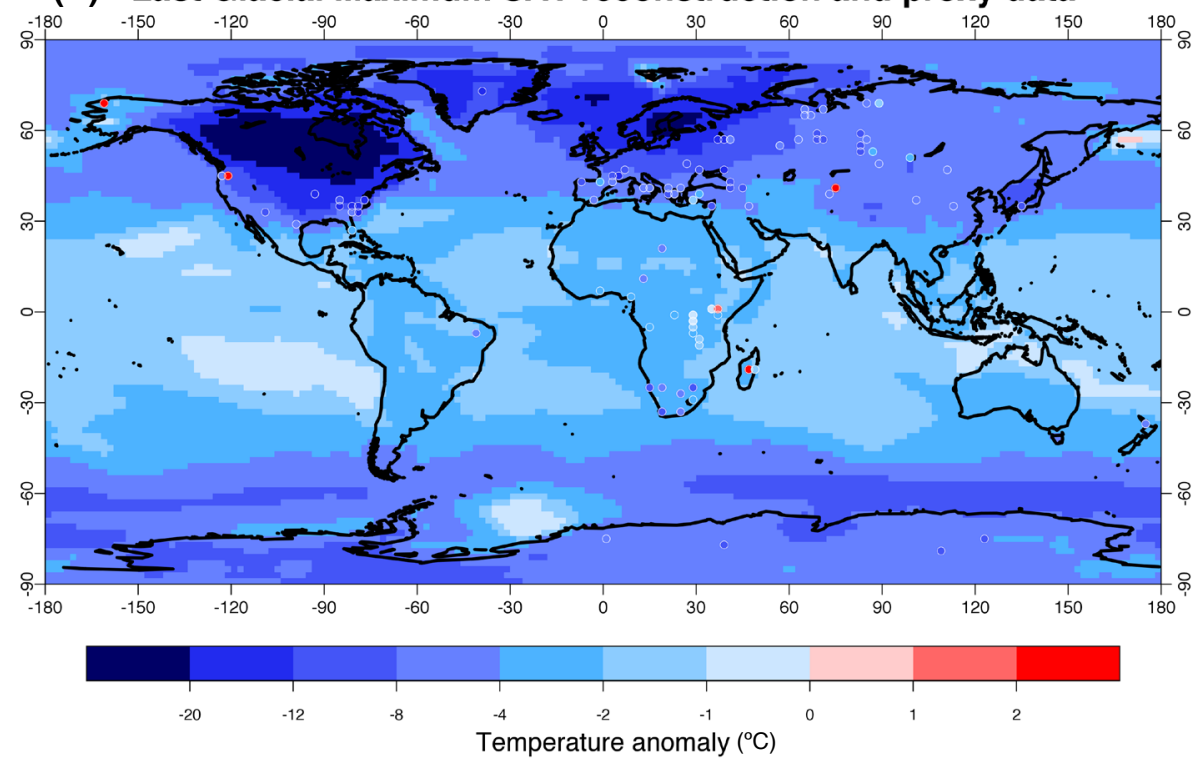

(B)

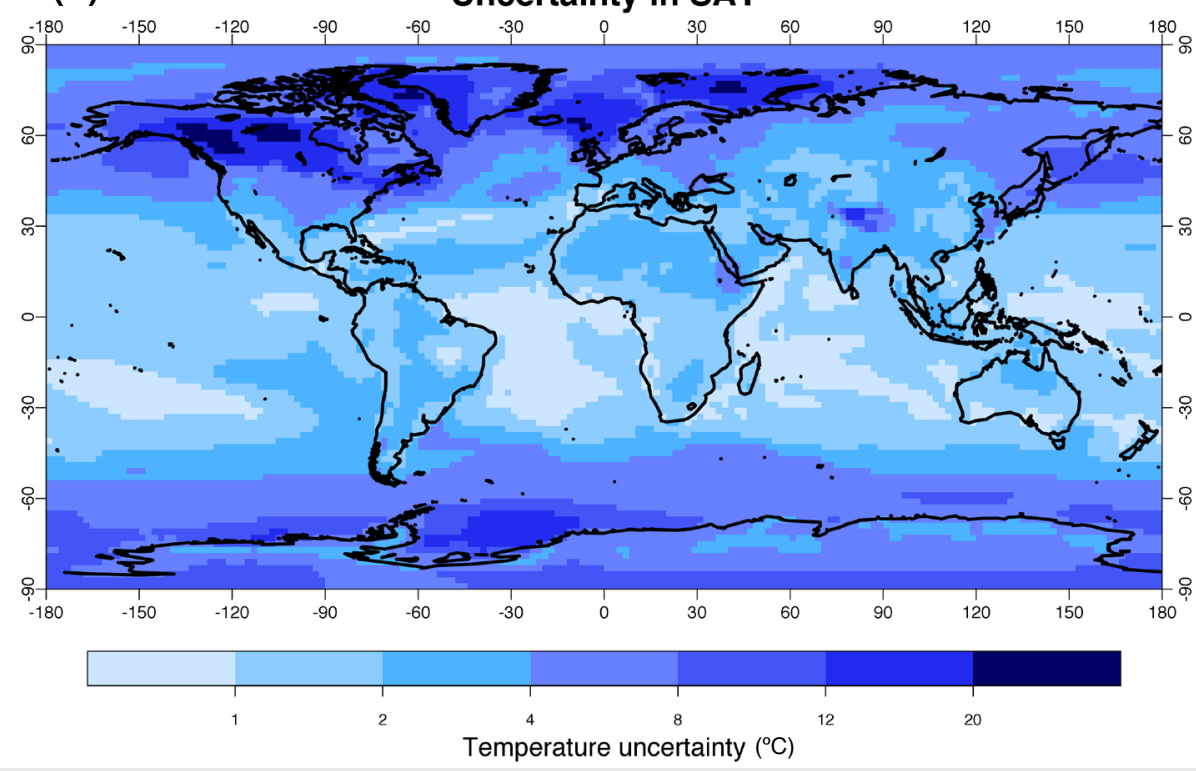

Figure 1: (A) Reconstruction of Last Glacial Maximum surface air temperature anomaly $\left({ }^{\circ} \mathrm{C}\right)$ based on multimodel regression. Proxy data are represented as colored dots. (B) Uncertainty in Last Glacial Maximum surface air temperature anomaly $\left({ }^{\circ} \mathrm{C}\right.$ ) from bootstrap resampling. Results presented as half-width of $95 \%$ confidence interval (Fig. 1 and 3 from Annan and Hargreaves 2013). 


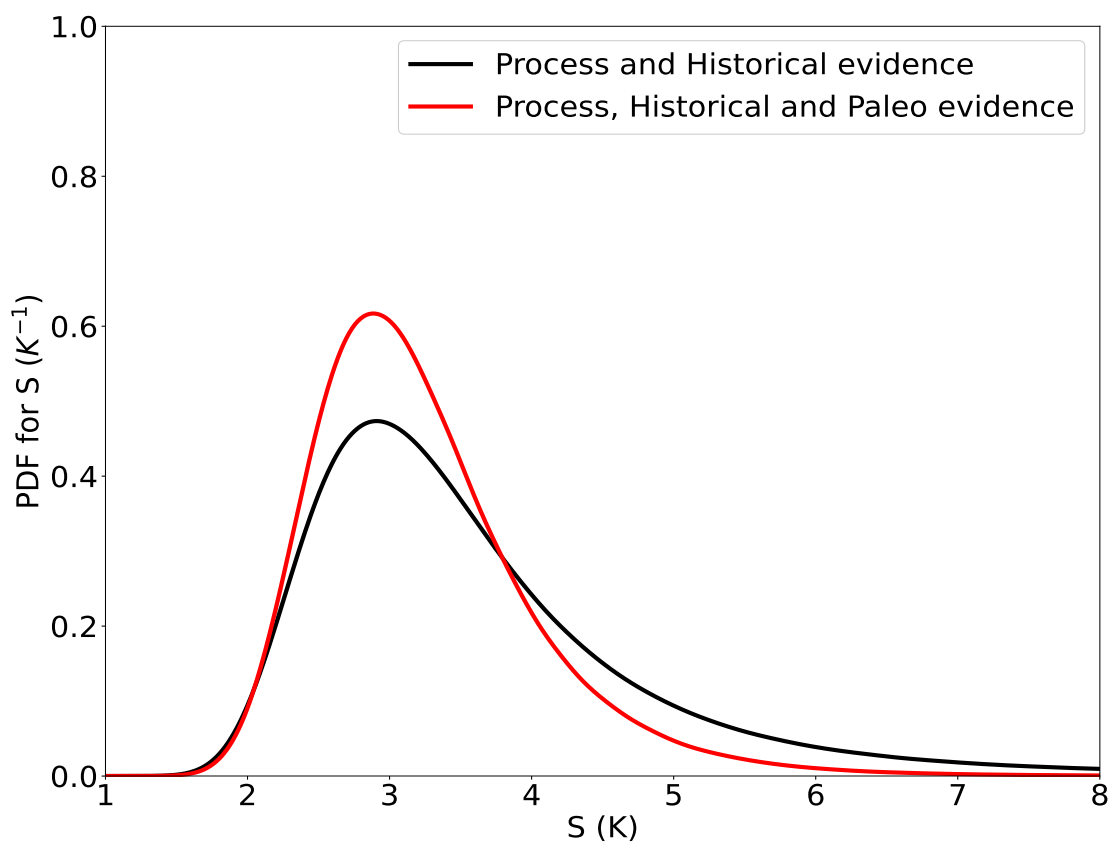

Figure 2: Estimated PDFs for climate sensitivity (S) with and without using paleo information, based on the values estimated by Sherwood et al. (2020). The baseline 66\% range not including paleo information was $2.6-4.6 \mathrm{~K}$. Including the paleoclimatic constraint, the range tightens to $2.6-3.9 \mathrm{~K}$.

sensitivity by Sherwood et al. (2020) included a substantial paleoclimate component and involved several P2F members working alongside researchers with primary expertise in the interpretation of paleodata. Results from PMIP activities influenced almost every aspect of the paleoclimate component of the assessment.

For example, in order to estimate climate sensitivity using paleoclimates, an estimate of the large scale temperature changes for paleoclimates relative to modern is required. Figure 1 shows a reconstruction of the Last Glacial Maximum temperature anomaly that was included in the evidence for the assessment. This estimate (from Annan and Hargreaves 2013) was a result of the P2F working group activities, and combined information from the PMIP2 ensemble and from climate proxy compilations (MARGO Project Members 2009; Bartlein et al. 2011; Schmittner et al. 2011). Uncertainty estimates are critical to these kinds of assessments, and the estimated uncertainties in this reconstruction are shown in the lower sub-figure. Figure 2 shows the baseline result from Sherwood et al. (2020), and the result that would be obtained if paleoclimate information was, instead, entirely ignored. It is clear that the paleoclimatic component significantly constrains the high end of the assessed range for climate sensitivity.

The assessment also made significant progress on one of the other goals of the working group: reconciling the previously divergent estimates of climate sensitivity from different constraints, which were found to be due in part to the pattern effect (Andrews et al. 2018) and some differences in the precise definitions of climate sensitivity that had been used. An emergent constraint is the term used to describe model variables for which measurements are available which may, through use of the multi-model ensemble, be used to refine probabilistic estimates of future climate change given certain emissions forcings. Members of the working group have further developed the use of emergent constraints to estimate climate sensitivity. Initial work focused on analyzing correlations between the Last Glacial Maximum (LGM) temperature anomaly and climate sensitivity, with the mid-Pliocene considered more recently (e.g. Hargreaves et al. 2012; Hopcroft and Valdes 2015; Hargreaves and Annan 2016). Recently Renoult et al. (2020) presented a Bayesian framework for combining emergent constraints from different periods, potentially including non-paleo emergent constraints. This method makes all assumptions explicit and enables emergent constraints to be incorporated into assessments of climate sensitivity, although some caveats remain.

Progress in regional climate change has usually been more qualitative and process based (e.g. Schmidt et al. 2014; Koh and Brierley 2015; Seth et al. 2019). Large-scale changes such as Arctic amplification and land-ocean contrast may be expected to be useful for constraining future climate but direct temperature comparisons have not so far indicated robust past-future relationships in the ensembles. However, detailed analyses of the processes involved in Arctic amplification may enable particular seasons for particular paleoclimate intervals to be used as constraints (LGM: Laîné et al. 2016; mid-Holocene: Yoshimori and Suzuki 2019). There is also potential for Arctic ice extent to be used to constrain likely future Arctic sea-ice changes (Last Interglacial: Kageyama et al. 2021). The merger of P2F with Paleovar (to make P2Fvar) in PMIP4 has increased the range of spatial and temporal scales being studied (Rehfeld et al. 2020; Brown et al. 2020; D'Agostino et al. 2020), a trend which we hope to see continue.

In addition to developing the more regional focus, the simulations of the last deglaciation which have been performed within PMIP have the potential to develop towards a new P2F activity of directly paleoclimateconstrained projections, as modelers extend the deglaciation runs into the next centuries (Fieg et al. 2021).

In summary, even with relatively few scientists working primarily in this area, the group is able to use the resources of PMIP, CFMIP, and CMIP, and has been very successful in raising the profile of paleoclimate as a topic of increasing interest to a wide range of researchers.

\section{AFFILIATION}

Blue Skies Research Ltd, Settle, UK

\section{CONTACT}

Julia C. Hargreaves: jules@blueskiesresearch.org.uk

\section{REFERENCES}

Andrews T et al. (2018) Geophys Res Lett 45: 8490-8499 Annan JD, Hargreaves JC (2013) Clim Past 9: 367-376

Bartlein P et al. (2011) Clim Dyn 37: 775-802

Brown JR et al. (2020) Clim Past 16: 1777-1805

Crucifix M et al. (2012) Eos 93: 539-539

D'Agostino R et al. (2020) J Clim 33: 9595-9613

Fieg R et al. (2021) EGU General Assembly 2021, 19-30 Apr 2021, EGU21-11083

Hargreaves JC, Annan JD (2016) Clim Past 12: 1591-1599 Hargreaves JC et al. (2012) Geophys Res Lett 39: L24702 Hopcroft PO, Valdes PJ (2015) Geophys Res Lett 42: 5533-5539

Kageyama M et al. (2021) Clim Past 17: 37-62

Koh JH, Brierley CM (2015) Clim Past: 11: 1433-1451 Laîné A et al. (2016) J Clim 29: 3297-3316 MARGO Project Members (2009) Nat Geosci 2: 127-132 Rehfeld Ket al. (2020) Earth Syst Dyn 11: 447-468 Renoult M et al. (2020) Clim Past 16: 1715-1735 Schmidt GA et al. (2014) Clim Past 10: 221-250 Schmittner A et al. (2011) Science 334: 1385-1388 Seth A et al. (2019) Curr Clim Change Rep 5: 63-79 Sherwood SC et al. (2020) Rev Geophys 58: e2019RG000678

Yoshimori M, Suzuki M (2019) Clim Past 15: 1375-1394 